Part of Journal of Research of the National Bureau of Standards, Volume 24, May 1940

\title{
PECTIC SUBSTANCE IN COTTON AND ITS RELATION TO THE PROPERTIES OF THE FIBER*
}

\author{
By Roy L. Whistler, Albert R. Martin, and Milton Harris ${ }^{1}$
}

\begin{abstract}
Evidence is presented which indicates that a pectin-cellulose compound does not exist in native cotton fibers and that the pectic substance is present as the insoluble salt of polyvalent ions. Replacement of these ions by sodium or ammonium renders the pectic substance soluble.

Cotton freed of pectic substance with alkali showed no significant change in tensile strength or in viscosity, whereas treatment of the fibers with acids, which removed only a small proportion of the pectic substance, produced an appreciable lowering of these two properties.

When dewaxed fibers were dispersed in cuprammonium hydroxide solutions, it was found that a small portion remained insoluble. Analysis of the material showed it to consist practically entirely of pectic substance. A consideration of these results led to the conclusion that pectic substance does not contribute to the viscosity of cuprammonium dispersions of cotton. Determinations of the viscosities of cuprammonium solutions to which had been added pectic material from different sources substantiated this conclusion.
\end{abstract}

\section{CONTENTS}

I. Introduction

II. Materials and methods

III. Experimental results and discussion

1. Extraction of pectic substance from cotton by different reagents _ 557

(a) Sodium hydroxide _._.

(b) Ammonium hydroxide

(c) Water

(d) Ammonium oxalate.

(e) Acetic acid

(f) Concentrated hydrochloric acid

2. State of the pectic substance in cotton fibers

3. Relation of the pectic substance to the properties of cotton fibers -561

4. Behavior of cotton fibers in cuprammonium hydroxide solutions 562

IV. References 564

\section{INTRODUCTION}

Polyuronides in the form of pectic substance ${ }^{2}$ have long been known to be present in naturally occurring cotton fibers. The current concepts regarding the location of this substance in situ, indicate at least two divergent viewpoints. Anderson and Kerr [1], ${ }^{3}$ for example,

\footnotetext{
${ }^{*}$ This paper was presented before the Cellulose Division at the ninety-ninth meeting of the American Chemical Society, Cincinnati, Ohio.

1 Research Associates at the National Bureau of Standards, representing the Textile Foundation.

${ }^{2}$ In the present paper, the term "pectic substance" is used to denote that carbohydrate component of native cotton which is characterized by the presence of uronic acid groups [3].
}

3 Figures in brackets indicate the literature references at the end of this paper. 
have recently presented evidence based on staining reactions and solubility tests which indicates that the pectic substance is restricted to the primary wall. On the other hand, Farr and Eckerson [2] stated that they believed the pectic substance to be the material covering the cellulose particles, the cellulose fibrils, as well as the fiber itself. The differences in these concepts necessarily led to very different conclusions concerning the influence of the pectic substance on many of the important properties of cotton.

Since the experimental evidence on which the previous viewpoints were based was essentially of a qualitative nature, it appeared that more precise information concerning the role of the pectic substance could only be obtained by a quantitative approach to the problem. The principal difficulty heretofore encountered in attempts to do this has been the lack of a reliable method for the quantitative estimation of the pectic substance in the presence of other carbohydrate material. Recently, however, a new method [4] was developed which permits the accurate determination of small amounts of uronic acids even in the presence of large proportions of cellulose. This development has made possible the present investigation, which concerns itself with (a) an examination of the state of the pectic substance in native cotton fiber, (b) its ease of removal by various reagents, (c) its behavior in cuprammonium hydroxide solutions, and (d) its influence on such important properties of the cotton as tensile strength and fluidity in cuprammonium hydroxide solution.

\section{MATERIALS AND METHODS}

The cotton used in these experiments was furnished by the Bureau of Agricultural Economics, United States Department of Agriculture. It was of the Missdel-7 variety, grown at the Delta Experiment Station at Stoneville, Miss., and had been ginned and twice carded but had received no chemical treatments.

The cotton was dewaxed by extraction with cold alcohol and with ether for 24 hours each. The dewaxed cotton had a copper number of 0.18 , a cuprammonium hydroxide fluidity of 0.95 rhe, a tensile strength of $89,300 \mathrm{lb} / \mathrm{in}^{2}{ }^{2}$, and a uronic acid content equivalent to 2.4 $\mathrm{mg}$ of carbon dioxide per gram of cotton. On the basis of these analyses, it may be considered to represent a high-grade natural cellulose.

The copper numbers were determined by a modification [5] of the Schwalbe-Braidy [6] procedure. In order to insure more uniform contact of the cellulose and reagent, the fibers were ground in a laboratory Wiley mill until they passed through a No. 20 screen.

Most of the measurements of the fluidities of the dispersions of cotton in cuprammonium hydroxide solutions were made according to the recommendations of Mease [7]. This procedure is essentially that set forth by the Fabrics Research Committee (London) [8], except that the higher concentration of ammonia originally recommended by Clibbons and Geake [9] was used. The cuprammonium hydroxide solution contained $240 \pm 5 \mathrm{~g}$ of ammonia $\left(\mathrm{NH}_{3}\right), 15 \pm 0.1 \mathrm{~g}$ of copper, and $1 \mathrm{~g}$ of sucrose per liter. The concentration of nitrite was less than 0.5 percent. In the present paper, this solution will hereafter be referred to as cuprammonium hydroxide solution $A$. All measurements were made on 0.5 -percent dispersions of cotton at $21^{\circ} \mathrm{C}$. 
In some of the experiments, a second cuprammonium hydroxide solution, prepared according to the specifications set forth by the Division of Cellulose Chemistry of the American Chemical Society [10] was used. This solution contained $30 \pm 2 \mathrm{~g}$ of copper, $165 \pm 2 \mathrm{~g}$ of ammonia, and $10 \mathrm{~g}$ of sucrose per liter. The concentration of nitrite was less than 0.5 percent. In the present paper, this solution will hereafter be referred to as cuprammonium hydroxide solution $B$.

Uronic acid determinations were made according to the method developed by Whistler, Martin, and Harris [4]. This procedure depends upon an examination of the rate at which carbon dioxide is evolved from a sample during treatment with a boiling solution of 12-percent hydrochloric acid. The results are recorded either as milligrams of uronic acid-carbon dioxide per gram of material, or as percentage of pectic substance. The latter value was obtained by multiplying the value for carbon dioxide (in percent) by the factor 4.8 [4].

Tensile-strength measurements were made by the improved Chandler bundle technique [11]. ${ }^{4}$

\section{EXPERIMENTAL RESULTS AND DISCUSSION}

\section{EXTRACTION OF PECTIC SUBSTANCE FROM COTTON BY DIFFERENT REAGENTS}

The experiments listed in this section are concerned with a variety of treatments to which cotton fibers have been subjected for various purposes in the course of several different investigations in progress in this laboratory. Accordingly, the conditions are not strictly comparable, and furthermore no attempt was made to remove all of the pectic substance with each of the reagents used. However, the application of the new method for the determination of uronic acids to the treated samples has made it possible to evaluate quantitatively the efficiency of the different reagents, and for that reason, it appeared advisable to include the results in the present paper.

\section{(a) SODIUM HYDROXIDE}

The treatment of cotton with a boiling 1-percent solution of sodium hydroxide has been recommended [12] for the preparation of standard cellulose. In an earlier investigation [4], it was found that cotton purified in this manner is free from uronic acids. In order to study the efficiency of the removal of pectic substance under these conditions, samples of cotton were similarly treated for different lengths of time. The procedure was essentially the same as that described by Corey and Gray [12], except that the apparatus of Worner and Mease [13] was employed. The extreme rapidity with which these solutions remove the pectic substance from cotton is shown by the uronic acid determinations in table 1 and figure 1 . Since the carbon dioxiderate curves for the samples treated for periods of $1 / 2$ hour or longer are the same and no longer exhibit the initial rapid rise characteristic of uronic acids, it appears that removal of the pectic substance is essentially complete in $1 / 2$ hour. The good agreement between the data for the samples treated for periods of $1 / 2$ hour or longer is indicative of the reproducibility of the results obtained by this method.

\footnotetext{
4 Thanks are due Robert W. Webb and Enoch Karrer, of the Division of Cotton Marketing, United States Department of Agriculture, for making these measurements.
} 


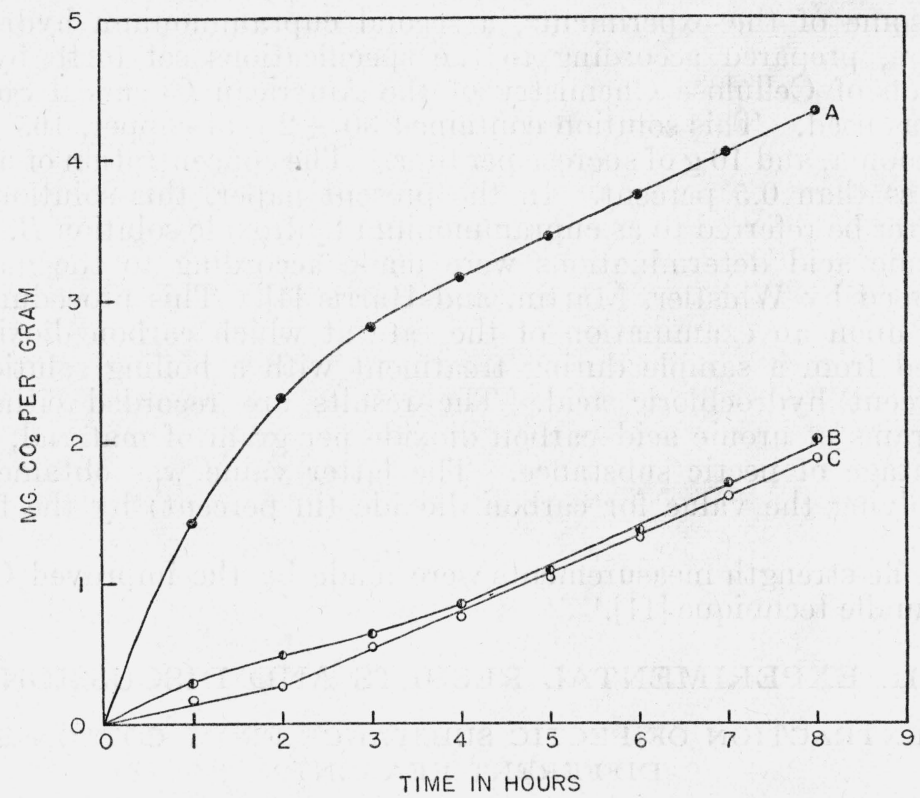

FIGURE 1.-Rate of evolution of carbon dioxide from dewaxed cotton and from cotton extracted for different lengths of time with a boiling 1-percent solution of sodium hydroxide.

Curve $A$ represents the rate of evolution from raw dewaxed cotton; curve $B$, the values for a sample treated for 10 minutes, and curve $C$ the value for samples of cotton treated for $1 / 2,2,4$, and $71 / 2$ hours. The points for these samples on curve $C$ were so close together that only one set is plotted in the figure.

TABLE 1.-Amount of carbon dioxide evolved, as a function of time, from cotton which had been extracted for different lengths of time with boiling 1-percent solutions of sodium hydroxide

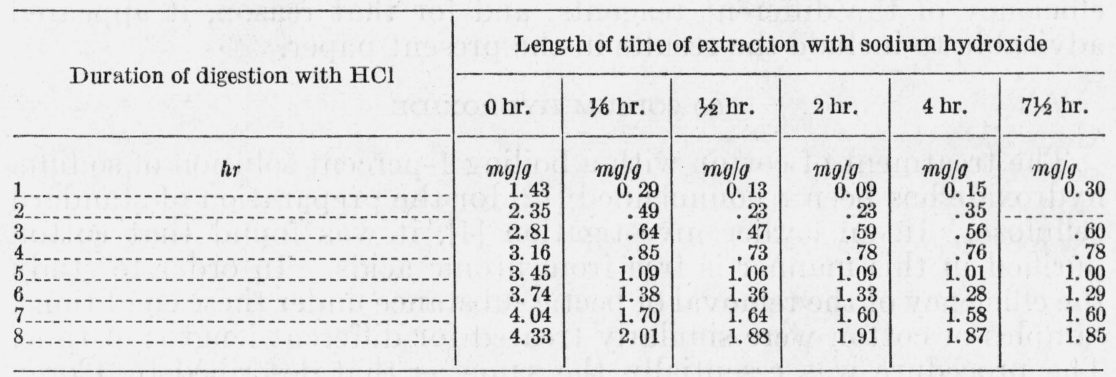

Cold solutions of sodium hydroxide were much less efficient in removing the pectic substance from the cotton. This was demonstrated by immersing samples for 20 hours in a 1-percent solution of sodium hydroxide at $30^{\circ} \mathrm{C}$. The usual precautions to exclude oxygen from the system were taken. The alkali solutions were always saturated with nitrogen and kept under nitrogen during the time they were in contact with the fiber. After these treatments, the samples were thoroughly washed with a cold, 1-percent solution of acetic acid and then with water. Analyses showed that the sample still contained an amount of uronic acid equivalent to $1.2 \mathrm{mg}$ of carbon dioxide per gram of cotton. From a comparison with the value of $2.4 \mathrm{mg}$ per 
gram for untreated cotton, it appears that only about 50 percent of the pectic substance was removed by the alkali under these conditions.

\section{(b) AMMONIUM HYDROXIDE}

Dewaxed cotton lost only about 10 percent of its pectic substance during extraction for 18 hours with a cold $\left(0^{\circ}\right.$ to $\left.3^{\circ} \mathrm{C}\right) 2$-percent solution of ammonia. However, when the cotton was first deashed by one of two treatments, to be described later, the pectic substance was readily removed under the same conditions. The solubility of the pectic substance of deashed cotton is striking, and as will be shown in section 2, use may be made of the phenomenon to isolate the pectic substance from cotton fibers.

\section{(c) WATER}

Cold water was found to be ineffective for removing pectic substance from native cotton, and hot water was only slightly more effective. A sample of dewaxed cotton, extracted with distilled water at $90^{\circ}$ to $95^{\circ} \mathrm{C}$ for 16 hours, yielded $2.1 \mathrm{mg}$ per $\mathrm{g}$ of uronic acid-carbon dioxide. This is equivalent to a loss of approximately 12 percent of pectic substance.

\section{(d) AMMONIUM OXALATE}

Ammonium oxalate solutions have been widely used as solvents for the extraction of pectic substance from fibers, fruits, etc. A sample of the dewaxed cotton was therefore subjected to two successive 8-hour extractions with 0.5 -percent solutions of this reagent at $75^{\circ}$ to $80^{\circ} \mathrm{C}$. The treated samples were washed with distilled water until oxalate iron could no longer be detected in the washings. Analyses of the treated material showed that it retained only $0.3 \mathrm{mg}$ of uronic acidcarbon dioxide per gram, and that about 90 percent of the pectic substance was removed by the above treatments.

\section{(e) ACETIC ACID}

A boiling 1-percent solution of acetic acid was found to remove less than 50 percent of the pectic substance in 8 hours. On the other hand, cotton treated overnight at room temperature with a 96-percent solution of acetic acid ${ }^{5}$ for the purpose of lowering its ash content showed no loss in pectic substance.

\section{(f) CONCENTRATED HYDROCHLORIC ACID}

A sample of dewaxed cotton was allowed to stand at room temperature (about $30^{\circ} \mathrm{C}$ ) in a hydrochloric acid solution of sp gr 1.18 for 4 hours. During this treatment, the fibers were degraded to a fine meal which was difficult to filter from the acid solution. The separated material was washed with water until free of acid and air dried. Analyses of the residue indicated that it had lost only about 20 percent of its pectic substance.

5 This concentration was suggested by C. B. Purves, of the Massachusetts Institute of Technology, since he had found that with higher concentrations of acetic acid, some acetylation of the fiber occurred. 


\section{STATE OF THE PECTIC SUBSTANCE IN COTTON FIBERS}

Although some naturally occurring pectic substance is soluble in warm water, the modification most often encountered is not readily dissolved and appears to become soluble only after chemical treatment. The insoluble material as it exists in the native state has been termed protopectin [3]. This substance, on chemical treatment, is presumably converted to a soluble pectic substance. It is in respect to the nature of the insoluble form of pectin that many differences of opinion have arisen.

Some investigators $[14,15]$ believe that a pectin-cellulose compound exists, which must first be hydrolyzed, before extraction of the pectin is possible. For example, Carré [16] has shown that pectin from several sources appeared to be removed only after treatment with hot dilute acids, such as $0.01 N$ hydrochloric or 0.5 -percent solutions of oxalic or citric acid. Others $[17,18]$ have suggested that natural pectin occurs in combination with certain metallic ions as insoluble salts. In support of this is the finding that calcium pectate is one of the constituents of the middle lamella of plant tissues [19].

The results described below, as well as those of a separate investigation, ${ }^{6}$ on the acidic properties of cotton fibers indicate that a pectincellulose compound does not exist in raw cotton fibers, and that the pectic substance is present on the fibers as insoluble salts of such polyvalent ions as calcium, magnesium, and iron [20]. If such a conclusion is correct, it should be possible to convert the native, insoluble pectic substance in cotton to the soluble form, without hydrolysis or other degradation, simply by substituting monovalent cations, such as sodium or ammonium, for the polyvalent cations mentioned above.

As has previously been mentioned, ammonium oxalate solutions have frequently been used by a number of investigators for the purpose of removing pectic substance from cotton fibers. Presumably, the pectic substance is converted to a soluble form by a process of double decomposition. Unfortunately, this evidence has not been considered conclusive, since the extraction process is carried out at elevated temperatures, and the experiments are therefore open to the criticism that some hydrolysis of the pectic substance may have occurred.

The pectic substance can be removed, however, at low temperatures, where the possibilities for hydrolysis are at a minimum. In section III, 1 (b) it was shown that cold $\left(0^{\circ}\right.$ to $\left.3^{\circ} \mathrm{C}\right)$ dilute solutions of ammonia had very little solvent effect on the pectic substance of dewaxed cotton, but that after the fiber had undergone treatments which removed the ash, the solubility of this substance was greatly increased in the same reagent.

The ash was readily removed, either by extraction with a 96 -percent solution of acetic acid or by electrodialysis in distilled water. The ash-free fiber was allowed to stand overnight in a 2-percent solution of ammonia at $0^{\circ}$ to $3^{\circ} \mathrm{C}$. Analysis of the treated material showed that about 90 percent of the pectic substance had been removed. Although there was no evidence of hydrolysis when the 96-percent acetic acid was used, this procedure may still be open to the same criticism given for the use of ammonium oxalate. This criticism is least applicable to the electrodialysis method of removal of ash, yet

o The results of this investigation are being prepared for publication: 
the pectic substance from samples so treated was as readily removed as from samples treated with 96-percent acetic acid. The ease with which the pectic substance is removed from deashed cotton was even more strikingly demonstrated in titration experiments (see footnote 6), where it was shown that removal of this substancelbegins when only very small amounts of dilute alkali have been added and the $\mathrm{pH}$ of the solution still remains on the acid side of neutrality.

It appeared that it would be of some interest to isolate the pectic substance removed from the deashed fibers and to compare it with a sample of the material obtained by the commonly used ammonium oxalate method. The material was recovered by the following procedure. The ammoniacal extract was made acid with hydrochloric acid, whereupon a large proportion of the pectic substance precipitated and was removed by filtration. The filtrate was neutralized and concentrated at $40^{\circ} \mathrm{C}$ under reduced pressure to a small volume, and the remainder of the pectic substance precipitated by pouring the concentrate into an excess of cold ethanol. The precipitates were combined, dissolved in hot water, and dialyzed for 24 hours. The material was again precipitated by pouring the dialyzed solution into cold ethanol. The precipitate was then filtered off, washed with ethanol and with acetone, and finally dried in air. A comparison of the material with a sample of pectic substance obtained by the ammonium oxalate method is given in table 2 . The values for the uronic acid-carbon dioxide contents of both samples are in good agreement. The fluidity of the sample obtained by the ammonium oxalate treatment is a little higher and is suggestive of the possibility that a small amount of hydrolysis of the pectic substance prepared by this method had occurred.

TABLE 2.-Comparison of a sample of pectic substance, obtained by extraction of deashed cotton with dilute ammonia solutions at $O^{\circ}$ to $S^{\circ} \mathrm{C}$, with that obtained from dewaxed cotton by the ammonium oxalate method

\begin{tabular}{|c|c|c|}
\hline $\begin{array}{c}\text { Method of isolation of pectic } \\
\text { substance }\end{array}$ & $\begin{array}{l}\text { Uronic acid- } \\
\text { carbon diox- } \\
\text { ide }\end{array}$ & $\begin{array}{l}\text { Fluidity of } 0.5 \\
\text { percent aque- } \\
\text { ous solutions } \\
\text { adjusted to pH } \\
\text { i } 8.1(\text { tempera- } \\
\text { ture } 21^{\circ} \mathrm{C} \text { ) }\end{array}$ \\
\hline $\begin{array}{l}\text { Ammonium oxalate........ } \\
\text { Ammonia }\end{array}$ & $\begin{array}{l}\text { Percent } \\
20.8 \\
21.1\end{array}$ & $\begin{array}{c}\text { Rhes } \\
23 \\
20\end{array}$ \\
\hline
\end{tabular}

\section{RELATION OF THE PECTIC SUBSTANCE TO THE PROPERTIES OF COTTON FIBERS}

The ease with which the pectic substance is removed from deashed cotton fibers, as indicated in the preceding section, strongly suggests that a chemical union between the pectic substance and the cellulose does not exist. Furthermore, it would be expected that if such a combination did exist, removal of the pectic substance would require chemical cleavage of covalent linkages which might result in an alteration of the properties of the fibers. That this does not appear to be the case is shown by the data in table 3 , which relate the pectic content to the tensile strength, copper number, and fluidity in cuprammonium hydroxide solutions of the cotton. 
TABLE 3.-Relation of pectic substance content of cotton to some of the properties of the fiber

\begin{tabular}{|c|c|c|c|c|}
\hline Treatment & $\begin{array}{l}\text { Content } \\
\text { of pectic } \\
\text { substance }\end{array}$ & $\begin{array}{l}\text { Tensile } \\
\text { strength }\end{array}$ & Fluidity & $\begin{array}{l}\text { Copper } \\
\text { number }\end{array}$ \\
\hline Dewaxed cotton. & $\begin{array}{l}\text { Percent } \\
1.15\end{array}$ & $1,000 \mathrm{lb} / \mathrm{in} .{ }^{2}$ & $\begin{array}{l}\text { Rhes } \\
0.95\end{array}$ & \\
\hline 0.5 -percent ammonium oxalate at $75^{\circ}$ to $80^{\circ} \mathrm{O}$ for $16 \mathrm{hr}$ & 0.14 & 89.8 & 1.1 & .02 \\
\hline $\begin{array}{l}\text { Boiling 1-percent socium hydroxide for } 2 \mathrm{hr} \\
\text { Concentrated hydrochloric acid (sp gr } 1.18 \text { ) at } 30^{\circ} \mathrm{C} \text { for }\end{array}$ & .00 & 94.2 & & .01 \\
\hline $4 \mathrm{hr}$ & .92 & 0.0 & 49.0 & 2.15 \\
\hline Boiling 1-percent acetic acid for $8 \mathrm{hr}$ & .60 & 86.7 & 5.7 & 0.20 \\
\hline $\begin{array}{l}\text { Electrodialyzed } \\
\text { Electrodialyzed sample treated with 2-percent ammonia }\end{array}$ & & 100.2 & &. \\
\hline $\begin{array}{l}\text { Electrodialyzed sample treated with 2-percent ammonia } \\
\text { at } 0^{\circ} \text { to } 3^{\circ} \mathrm{C} \text { for } 15 \mathrm{hr}\end{array}$ & 0.19 & 97.7 & 1.4 & .02 \\
\hline
\end{tabular}

In agreement with the results of earlier workers [21], it may be seen that there is a relationship between the decrease in tensile strength and the increase in cuprammonium hydroxide fluidity. The most striking feature of these data, however, is found in the comparison of the properties of the fibers which had been treated with reagents such as ammonium oxalate or sodium hydroxide with those of fibers treated with acetic or hydrochoric acids. Cotton fibers freed from pectic substance by boiling in a 1-percent solution of sodium hydroxide for 2 hours exhibited tensile strengths which indicated that no damage had been done to them. Similarly, the tensile strength remained unchanged in those fibers from which most of the pectic substance was removed by ammonium oxalate extraction. These treatments appeared to effect an almost negligible increase in fluidity.

On the other hand, treatments with acetic or hydrochloric acid removed much smaller amounts of the pectic substance but produced appreciable changes in tensible strength and fluidity. This was especially noticeable in the sample treated with concentrated hydrochloric acid. The fiber structure was completely destroyed, yet the material lost only about 20 percent of its content of uronic acids. It might be argued, of course, that the hydrochloric acid had destroyed the structure of the pectic substance. Although quantitative evidence is lacking, qualitative examination of a sample of pectic substance, isolated from cotton fibers which had been treated with concentrated hydrochloric acid, as described in section 1 , showed that it still retained its gelatinous structure and appeared in many ways to be similar to pectic substance isolated by much less drastic methods.

\section{BEHAVIOR OF COTTON FIBERS IN CUPRAMMONIUM HYDROXIDE SOLUTIONS}

During the preparation of the cuprammonium hydroxide solutions of cotton fibers for fluidity measurements, it was observed that solutions of dewaxed cotton always showed a slight cloudiness, whereas solutions of cotton purified by treatment with a boiling 1-percent solution of sodium hydroxide (see section III, 1 (a)) were clear. An examination ${ }^{7}$ of the solutions under the microscope revealed the presence of an insoluble material having the appearance of the outer shell of the fiber. No such solid residue could be detected in solutions of the purified cotton. When the cloudy solutions were centrifuged,

\footnotetext{
7 The results of this investigation are being prepared for publication.
} 
a small amount of insoluble material was precipitated, and the solution became clear.

In order to study the phenomenon further, and to determine the nature of this precipitate, $28.5 \mathrm{~g}$ of dewaxed cotton was dissolved, by shaking for 20 hours, in 4 liters of cuprammonium hydroxide solution $A$. The resulting cloudy solution was centrifuged until it was practically clear. The precipitate represented 3.22 percent of the original cotton sample. On analysis, a sample of the precipitate gave the carbon dioxide-rate curve characteristic of uronic acids and yielded $58 \mathrm{mg}$ of carbon dioxide per gram. From this value it was estimated that 28 percent of the precipitate was pectic substance and that this accounted for about 70 percent of the pectic substance in the original sample of dewaxed cotton. When the precipitate was tested with ruthenium red [22], a considerable portion of it was stained red, which indicates the presence of pectic substance. With the iodine-sulfuric acid test, a portion of the material gave a blue color similar to that obtained with cellulose.

The relatively high percentage of pectic substance in the precipitate and the recovery of such a large proportion of the pectic substance of the dewaxed cotton were indeed striking. Since, however, some cellulose appeared to be present in the precipitate, the question immediately arose whether the precipitate was a stable cellulose-pectin compound or whether the pectic substance was contaminated, either with undissolved cellulose or with occluded, dissolved material. Some of the latter was undoubtedly always present, since a small portion of the cuprammonium solution was always retained by the precipitate. Although the evidence presented in section III, 2 and 3 , indicated that a compound of pectic substance and cellulose did not exist, it, nevertheless, seemed advisable to further investigate the nature of the precipitate obtained in this experiment.

Accordingly, the precipitate was resuspended in $200 \mathrm{ml}$ of fresh cuprammonium hydroxide solution and the mixture allowed to stand for 24 hours, after which the insoluble portion was again removed by centrifuging. This procedure was repeated three times, and the final precipitate was then washed with dilute acetic acid, followed by successive washings with acetone and with benzene. The product yielded $150.3 \mathrm{mg}$ of carbon dioxide per gram, which indicated that the bulk of the cellulosic material had been removed and that the residue consisted largely of pectic substance.

The material which remained in the cuprammonium hydroxide solution originally used to dissolve the dewaxed cotton, was precipitated by adding sufficient cold, dilute hydrochloric acid to bring the solution to neutrality. The precipitate was immediately washed with water and acetone, and then dried. On analysis the material gave a carbon dioxide-rate curve identical with that of glucose or cuprammonium rayon [4], which indicated the absence of detectable amounts of uronic acids.

In order to determine whether the concentrations of copper or ammonia in the cuprammonium hydroxide solutions had special solubility effects with respect to the pectic substance, the same experiments described above were repeated, using cuprammonium hydroxide solution $B$. On shaking dewaxed cotton (calculated to form 0.5 percent dispersion) with this solution, the cellulose quickly dispersed, leaving suspended in the mixture numerous bits of insoluble material, 
which, under the microscope, appeared to be identical with those described in the previous experiment. Since this cuprammonium hydroxide solution has a greater density than that used in the previous experiment, the insoluble material was somewhat more difficult to remove during centrifuging, and a smaller yield was obtained. The material was further purified with fresh cuprammonium hydroxide solution, as previously described. The final precipitate was stained a deep red with ruthenium red and was found to yield $153 \mathrm{mg}$ per gram of uronic acid-carbon dioxide, which indicated again that the fraction insoluble in cuprammonium hydroxide solutions is principally pectic substance.

Finally, the same experiment was done with cotton which had been treated for 4 hours with hydrochloric acid (sp gr 1.18). This treatment is similar to that which Farr [23] states will remove the cementing material, of which one component, it is further stated, is the pectic fraction of cotton fibers. As in the previous experiments, a fraction insoluble in cuprammonium hydroxide solution was obtained, and accounted for a large proportion of the pectic substance of the original fiber. On further purification of this fraction with fresh cuprammonium hydroxide solution, a product was obtained which yielded $164 \mathrm{mg}$ of carbon dioxide per gram. Qualitative examination of the final precipitate showed that it retained its gelatinous structure and appeared to be similar to the pectic substance isolated by other procedures.

A consideration of the results of the above experiments, as well as those shown in table 3 , leads to the conclusion that the pectic substance does not contribute to the viscosity of cuprammonium hydroxide dispersions of cotton fibers. Further evidence supporting this conclusion was obtained by shaking a 0.1 -gm sample ${ }^{8}$ of pectic substance, isolated from cotton, as well as similar amounts of commercial preparations of pectin ${ }^{9}$ andp ectic acid, ${ }^{10}$ in 20 -ml portions of cuprammonium hydroxide solution A for 4 days. At the end of this time, none of the materials appeared to have dissolved. Fluidity measurements of the cuprammonium hydroxide solution to which has been added the pectic substance from cotton showed it to be identical with the original cuprammonium hydroxide solution.

\section{REFERENCES}

[1] D. B. Anderson and T. Kerr, Ind. Eng. Chem. 30, 48 (1938).

[2] W. K. Farr and S. H. Eckerson, Contrib. Boyce Thompson Institute 6, 189 (1934).

[3] American Chemical Society Committee on Nomenclature of Pectin of the Agriculture Food Division. Definitions. J. Am. Chem. Soc. 49, Proc. 37 (1927).

[4] R. L. Whistler, A. R. Martin, and M. Harris, J. Research NBS 24, 13 (1940) RP1268.

[5] TAPPI, T430m.

[6] D. A. Clibbens and A. Geake, J. Textile Inst. 15, 27T (1924).

[7] R. T. Mease, J. Research NBS 22, 271 (1939) RP1179.

[8] Report of the Fabrics Research Committee, Department of Scientific and Industrial Research, His Majesty's Stationary Office, London (1933).

[9] D. A. Clibbens and A. Geake, J. Textile Inst. 19, T77 (1928).

${ }^{8} \mathrm{This}$ is approximately 100 times as much pectic substance as would be present in a regular fluidity determination of cotton.

- California Fruit Growers Exchange.

10 Eastman Kodak Co. 
[10] American Chemical Society. Committee on the Viscosity of Cellulose of the Division of Cellulose Chemistry. Ind. Eng. Chem., Anal. Ed., 1, 49 (1929).

[11] H. B. Richardson, T. L. W. Bailey, and C. M. Conrad, U.S. Dept. Agr. Tech. Bul. No. 545, P1 (1937).

[12] A. B. Corey and H. L. Gray, Ind. Eng. Chem. 16, 853 (1924).

[13] R. K. Worner and R. T. Mease, J. Research NBS 21, 609 (1938) RP1146.

[14] T. von Fellenberg, Biochem. Z. 85, 118 (1918).

[15] R. Sucharipa, J. Am. Chem. Soc. 46, 145 (1924).

[16] M. H. Carré, Biochem. J.19, 257 (1925).

[17] D. R. Nanji, F. T. Paton, and A. R. Ling, J. Soc. Chem. Ind. 44, 253T (1925),

[18] W. Kopaczewski, Bul. Soc. Chem. Biol. \%, 419 (1925).

[19] R. M. Tupper-Carey and J. H. Priestly, Proc. Royal Soc. (London) [B]. 95, 109 (1923).

[20] A. C. Walker and M. H. Quell, J. Textile Inst. 24, T131 (1933).

[21] D. A. Clibbens and B. P. Ridge, J. Textile Inst. 19, T394 (1928).

[22] L. Mangin, Compt. rend. 116, 653 (1893).

[23] W. K. Farr, Contrib. Boyce Thompson Inst. 10, 71 (1938).

Washington, February 12, 1940. 